\title{
Autosomal dominant keratitis
}

INSERM

\section{Source}

INSERM. (1999). Orphanet: an online rare disease and orphan drug data base. Autosomal dominant keratitis. ORPHA:2334

Hereditary keratitis is characterised by opacification and vascularisation of the cornea, often associated with macula hypoplasia. 